\title{
Birthing Support for Midwives and Mothers - Ergonomic Testing and Product Development
}

\author{
Nina Nevala ${ }^{*}, 1,2$ and Ritva Ketola ${ }^{1,3}$ \\ ${ }^{I}$ Finnish Institute of Occupational Health, Ergonomics and Usability, Topeliuksenkatu 41 a A, FI-00250 Helsinki, \\ Finland \\ ${ }^{2}$ University of Jyväskylä, Department of Health Sciences, Box 35, FI-40014 University of Jyväskylä, Finland \\ ${ }^{3}$ Eidos Ltd, Helsinki, Finland
}

\begin{abstract}
Purpose: To further develop an ergonomic birthing support for increasing comfortable postures for midwives and mothers during deliveries.

Methods and Results: First, the prototype of the birthing support and six birthing postures were tested with 8 midwives, 2 physicians, and 10 pregnant women in the last month of their pregnancy using visual analogue scales (VASs) and the System Usability Scale (SUS). According to the midwives and mothers, the best birthing postures were those with the mother sitting on the birthing support with the bed crosswise or the mother laying on her side on the bed with her leg on the birthing support. In the second stage of the study, 4 experts carried out an expert evaluation, and the company implemented several development points for the prototype. In the third stage, the developed birthing support was tested in 20 live births in two hospitals in Finland. The participants $(n=28)$ were 8 midwives and 20 pregnant women. The work postures, musculoskeletal strain, and the midwives' ability to see the work object were analysed. The midwives worked more with a straight back and perceived lower physical strain when the birthing support was used than in the traditional deliveries. The use of the birthing support also provided a better view of the emerging baby and perineum.

Conclusions: Use of the birthing support increased the adjustability of the midwives work environment and decreased their musculoskeletal exposure at work. The results of this study can be used in developing both the ergonomic work of midwives and comfortable birthing postures for mothers.
\end{abstract}

Keywords: Birth, birthing support, delivery, ergonomics, midwife, usability.

\section{INTRODUCTION}

Midwives' work includes awkward work postures and the use of muscular force due to the inadequate work environment and demands of the work tasks [1, 2]. In hospitals, awkward postures of midwives are typical when they are attending births, (in particular water births), assisting with breast feeding, and moving beds and other heavy equipment [3]. Furthermore, midwives experience work-related stress since the work is emotionally demanding and there are insufficient work resources and poor organisation at work [4].

Job demands, demanding work schedules, physical exposure, and job seniority are known to be associated with a high prevalence of lumbar and thoracic musculoskeletal disorders among health care workers (e.g. midwives) [5, 6]. If midwives work in front of the mother and use a suitable work level, their work postures are more ergonomic [2]. A good position for the midwife makes it possible for her to see the expression in the mother's eyes, her face, and her

Address correspondence to this author at the Finnish Institute of Occupational Health, Ergonomics and Usability, Topeliuksenkatu 41 a A, FI-00250 Helsinki, Finland; Tel: 040 7344166, 030 4742277;

E-mail: nina.nevala@ttl.fi whole body, all of which are important signals to a midwife [7]. By being present and offering trust, the midwife can positively influence a woman's experience of pain during childbirth $[8,9]$.

The effectiveness of adjustable work levels on musculoskeletal strain in the lower back and better satisfaction and productivity among health care workers have been reported with the use of electric beds [10], electrically adjustable shower trolleys [11], mobile terminals [12] and laboratory workstations [13].

Some studies have described the stress factors of midwives' work and mothers' experiences of their relationship with midwives. However, knowledge about new ergonomic solutions for more ergonomic postures for midwives and mothers is limited. The aim of our study was to further develop an ergonomic birthing support for increasing the use of ergonomic postures among midwives and comfortable postures of mothers during deliveries.

\section{METHODS AND RESULTS}

\section{Study Design}

This study was an experiment performed as a part of a product development process (Fig. 1). Ulrich and Eppinger [14] defined product development as a set of activities 


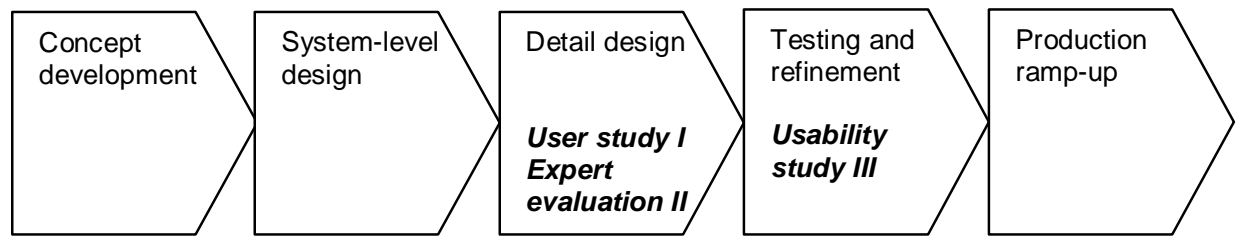

Fig. (1). The user study, expert evaluation, and usability study (phases I-III) as part of the product development process of a birthing support according to Ulrich and Eppinger [14].

starting with the perception of a market opportunity and ending with the production, sale and delivery of a product.

This study included the following three stages: a user study (I), an expert evaluation (II) and a usability study (III). In the first and second stages of the study, users and experts evaluated the prototype of the birthing support in simulated deliveries and provided feedback to the company. The outcome of both the user study and the expert evaluation was a list of requirements for a usable, ergonomically designed birthing support. In the usability study (III), the further developed birthing support was tested by midwives and mothers in actual birthing situations.

\section{Tested Birthing Support}

The tested birthing support, called relaxbirth ${ }^{\circledR}$ (Fig. 2), can be used with the mother in several positions in the opening and pushing phase of the delivery process. The design and the adjustable opening angle of the pushing handles provide for variation in use during the pushing phase, according to the height and preferences of the mother. The arm supports offer an opportunity to relax in the opening phase of the delivery process. The seat opening offers space for the midwife or physician to assist with the childbirth. Two wheels that turn make steering the birthing support possible. The birthing support can be equipped with an adjustable infusion stand, pushing straps to enhance the leverage force of the mother and a safety harness.

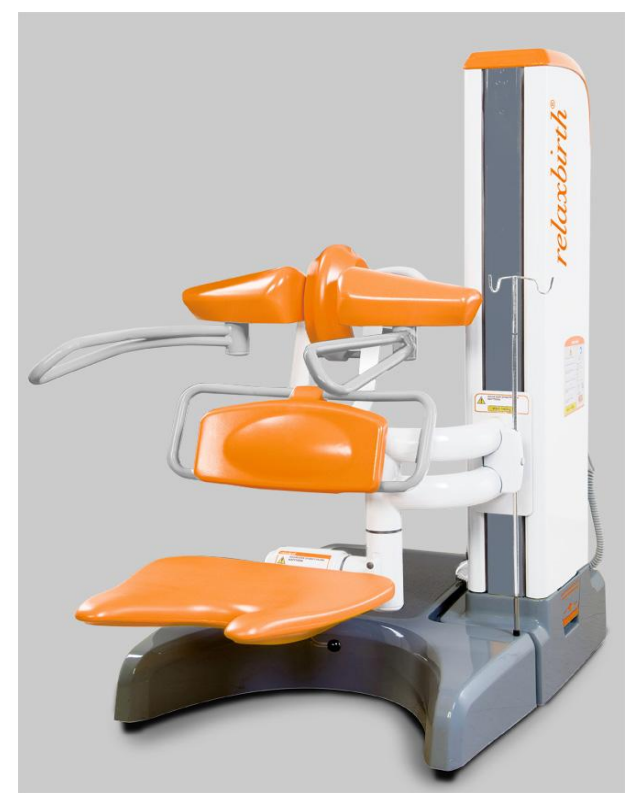

Fig. (2). Features of the tested birthing support: 1. Combined headrest, chest support and massager 2. Pushing handles, 3. Seat, 4. Arm supports, 5. Backrest 6. Backrest side handles.

\section{Ethical Considerations}

The Ethics Committee of the Helsinki University Hospital approved the current research. Furthermore, the Institutional Research Board of Helsinki City and the KantaHäme Hospital in Hämeenlinna gave their permission for the usability study. All of the participants were volunteers. They were individually informed of the study and gave their written consent to participate before the study began. Permission to video-record the test situation and real births was obtained from each midwife, doctor and mother.

\section{User Study (I)}

\section{Methods}

The prototype of the birthing support was tested in simulated birth situations in a delivery room in the Helsinki University Hospital. The tested birthing postures (Fig. 3) of the mother during the pushing phase were a) sitting on the birthing support with the bed crosswise, b) sitting on the birthing support with the bed lengthwise, c) side-lying on the bed with the leg on the birthing support, d) kneeling with the birthing support, e) half-sitting on the bed, and f) sitting on a traditional birthing chair. In this phase of the study, 8 midwives, 2 physicians, and 10 pregnant women in the last month of their pregnancy participated (Table 1). The female midwives and the physicians worked in the hospital. The mothers were recruited from the maternity clinics of the city. Midwives with work experience of at least 1 year in the hospital were informed and asked to contact the head midwife if they were willing to participate in the study.

The test simulation, lasting 2 hours, was planned in a participative way by the midwives, physicians and researchers. Before the test simulation, the midwife carried out an examination of the mother in another room to check the condition of the baby. The midwife led the simulated delivery process as in real deliveries. Before the test, the midwife or physician adjusted the birthing support (height, position of the handles and position of the decolte support) to provide an ergonomic work posture for the midwife and comfort for the mother. The test simulation was carried out peacefully, and the mother was able to pause when she wanted. Before the test, the midwife, physician and mother were instructed in the use and adjustment of the position of the birthing support.

Visual analogue scales (VASs) were used to evaluate the postures by determining the perceived posture and comfort of the midwives and mothers, the ability of midwives to see the work object, and the ability of mothers to breathe [14]. VAS lines were also used to evaluate the usability of different features of the product. The VAS is a $100-\mathrm{mm}$ long continuous line with end points anchored by 0 (very poor) 


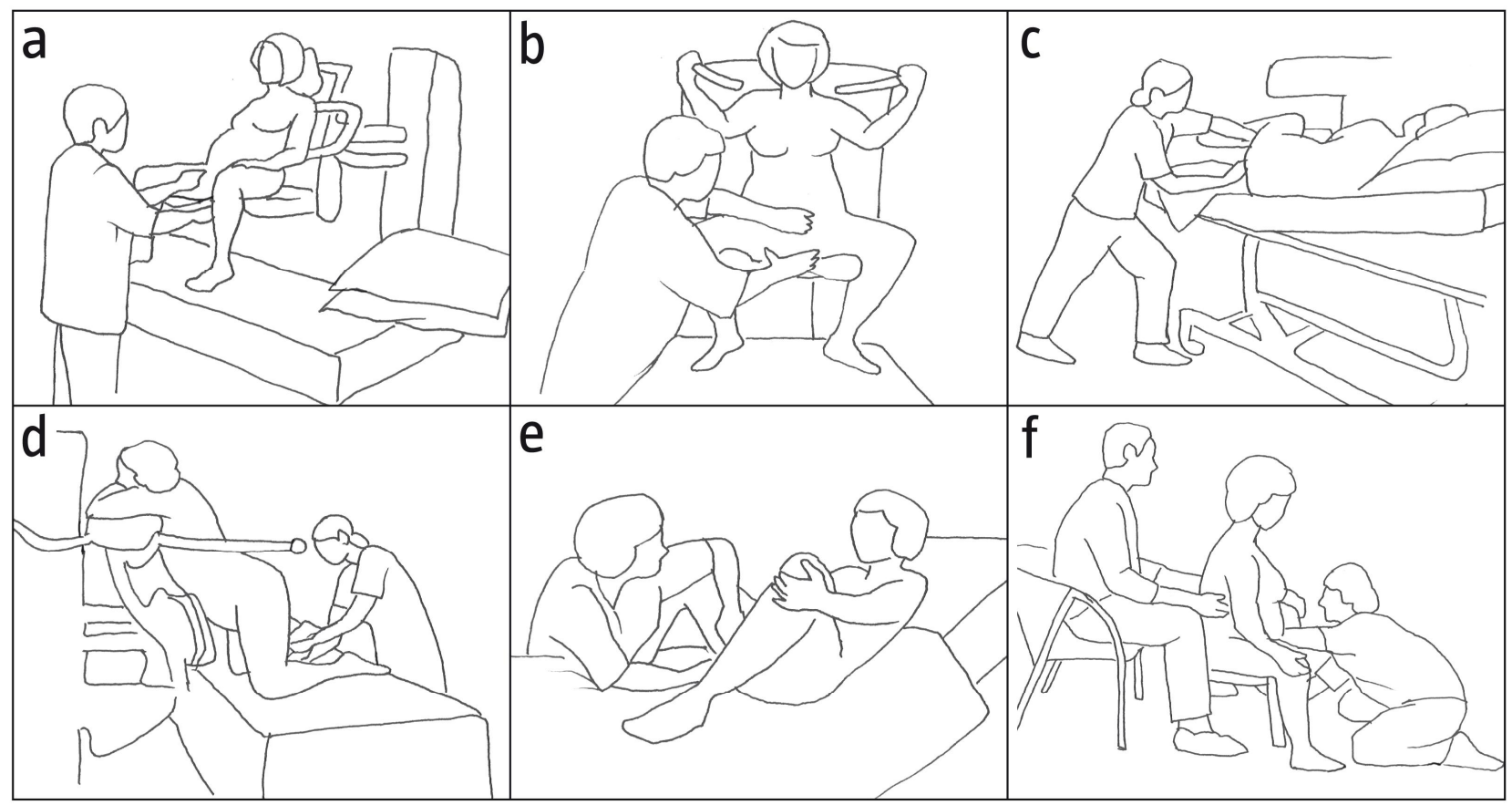

Fig. (3). The tested birthing postures of the mothers: a) sitting on the birthing support with the bed crosswise, b) sitting on the birthing support with the bed lengthwise, c) side-lying on the bed with a leg on the birthing support, d) kneeling with the birthing support, e) halfsitting on the bed, $\mathbf{f})$ sitting on the traditional birthing chair.

Table 1. The Background Factors of the Midwives, Physicians and Mothers in User Study (I) and Usability Study (III). The Values are Means and Ranges

\begin{tabular}{|l|c|c|c|c|}
\hline \multirow{2}{*}{ Variable } & \multicolumn{2}{|c|}{ User Study (I) } & \multicolumn{2}{c|}{ Usability Study (III) } \\
\cline { 2 - 5 } & Midwives, Physicians (n=10) & Mothers (n=10) & Midwives (n=8) & Mothers (n=20) \\
\hline \hline Age (years) & $43(29-55)$ & $31(24-37)$ & $42(26-59)$ & $29(22-36)$ \\
\hline Height (cm) & $167(158-176)$ & $169(162-175)$ & $165(158-170)$ & $168(162-177)$ \\
\hline Weight (kg) & $71(53-96)$ & $76(68-85)$ & $69(58-95)$ & $76(60-112)$ \\
\hline Pregnancy (week) & - & $38(37-40)$ & - & - \\
\hline Work experience (years) & $12(1-25)$ & - & $10(1-28)$ & - \\
\hline
\end{tabular}

and 100 (very good). The VAS score is a measured distance (expressed in millimeters) from the left-hand scale point.

The System Usability Scale (SUS) with 10 items was used to determine the global view of the subjective assessments of usability during the simulated delivery [16]. It provided an easy-to-understand score from 0 (negative) to 100 (positive). The SUS is an effective, reliable and inexpensive tool for measuring the usability of a wide variety of products and services [16].

\section{Results}

According to the midwives and mothers, the best birthing postures were when the mother was sitting on the birthing support with the bed crosswise and when the mother laid on her side on the bed with her leg on the birthing support (Table 2). These postures allowed the midwife to work in an ergonomic posture and see the object of her work well. Visibility was also good in the traditional posture, when the mother was half-sitting on the bed. The midwives rated the postures they had to use with the mother sitting on the traditional, low birthing chair as the poorest.

According to the mean SUS index, the usability of the birthing support was 68 (range 50-95) in the simulated situation. The SUS scores of the 10 midwives and physicians were $95,77.5,72.5,72.5,70,65,65,60,55$ and 50 .

According to the VAS, the adjustability of the birthing support, the design of the back rest, the functioning of the control unit, and the design of the whole BS were the usability factors with the highest ratings. On the other hand, movability, compatibility with the bed, and the functioning of the wheels received the lowest scores. 
Table 2. Subjective Assessment (VAS, $\mathbf{0}=$ Very Poor, $100=$ Very Good) of Work Posture, Visibility and Comfort Among the Midwives (n=10) and Posture, Ability to Breathe and Comfort Among the Mothers (n=10) when the Different Birthing Postures (A-F) of the Mothers Were Used in the Test Simulation. Values are Means (Standard Deviations, SD)

\begin{tabular}{|c|c|c|c|c|c|c|c|}
\hline & \multicolumn{6}{|c|}{ Birthing Posture $^{1}$} & $p^{2}$ \\
\hline Work posture & $75(14)$ & $25(22)$ & $71(24)$ & $74(14)$ & $59(25)$ & $31(22)$ & $<0.0001$ \\
\hline Visibility & $86(11)$ & $55(22)$ & $77(21)$ & $65(23)$ & $81(9)$ & $46(23)$ & 0.0004 \\
\hline \multicolumn{8}{|l|}{ Mothers (n=10) } \\
\hline Posture & $82(11)$ & $77(16)$ & $83(16)$ & $58(30)$ & $64(26)$ & $59(27)$ & 0.1 \\
\hline Ability to breathe & $85(12)$ & $76(16)$ & $83(14)$ & $64(22)$ & $60(29)$ & $76(17)$ & 0.2 \\
\hline Comfort & $77(13)$ & $73(15)$ & $82(16)$ & $58(29)$ & $61(31)$ & $62(24)$ & 0.2 \\
\hline
\end{tabular}

${ }^{1} \mathrm{~A}=$ Sitting on the birthing support with the bed crosswise, $\mathrm{B}=$ Sitting on the birthing support with the bed lengthwise, C=Side lying on the bed with a leg on the birthing support, $\mathrm{D}=$ Kneeling with the birthing support, $\mathrm{E}=$ Half-sitting on the bed, $\mathrm{F}=$ Sitting on the traditional birthing chair.

${ }^{2}$ Difference between the birthing postures, One-Way ANOVA (parametric test) or Kruskall-Wallis (non-parametric test), adjusted using Mann-Whitney.

\section{Expert Evaluation (II)}

The process started with a 2-hour expert evaluation [12, 17] in which 4 experts in ergonomics, design, health science and physiotherapy participated. In this hands-on session, the experts performed usage scenarios using the birthing support and commented on the physical design characteristics and the implementations of the prototype. One of the experts acted as chairman and motivated the discussion if needed. During the session, the experts were able to evaluate the use of the birthing support in simulated work situations from a video film taken in the user study.

The experts' comments were collected during the session as a list of recommended modifications for the birthing support. The development points for the birthing support were the adjustability of the handles in order for the mother to support her arms and help to produce the pushing force. For the midwives, adjustability is important for standing and sitting postures. According to the experts, the cleanability and movability still needed development (Table 3 ).

This list was handed to the developers of the birthing support so that the comments could be taken into account when a new version was designed. The company took into account the confidential suggestions.

\section{Usability Study (III)}

\section{Methods}

The developed birthing support was tested in 20 live births in two hospitals in Finland. The participants $(n=28)$ were 8 midwives and 20 pregnant women (Table 1). Ten of the mothers used the birthing support, and ten mothers used traditional birthing postures in their actual deliveries.

The pushing phase of the delivery was video-recorded, and the recordings were started by the midwives according to the advice of the researchers. The birthing postures used by the mothers were analysed from the video-recordings. The work postures of the midwives during the delivery process were analysed from the video-recordings with the use of the OWAS (Ovako Working-posture Analysing System) method [18]. The analyses were made from frozen frames every 10 seconds. Altogether 1274 work posture observations of the midwives were made during the deliveries with the birthing support, and 1468 observations were made without the BS. In every observation, the posture of the back, upper limbs and lower limbs and the used force of the midwife were analysed.

The VAS $(0=$ no strain, $100=$ extreme strain $)$ was used to assess the musculoskeletal strain of the midwives for four body parts (neck and shoulder, back, arms and legs) [15].

The usability of the birthing support and the physical strain of the midwives during the births were determined. The SUS with 10 items was used to determine the global view of usability among the midwives during the real deliveries [16].

The data are presented as mean values with standard deviations. Shapiro-Wilk test was used to test the normality of the data. For normally distributed variables the One-way

Table 3. The Evaluators (n=4) Who Found Development Points for the Birthing Support

\begin{tabular}{|c|l|l|}
\hline Evaluator & \multicolumn{1}{|c|}{ Education } & \\
\hline \hline 1 & Doctor of health sciences, physiotherapist & Adjustability of the handles, possibility for mother to support arms \\
\hline 2 & Doctor of health sciences, physiotherapist & Suitable for standing and sitting postures of midwives, cleanability, movability \\
\hline 3 & Doctor of sport sciences, physiotherapist & Adjustability of the height, ability for mothers to go to different postures, adjustability of the handles \\
\hline 4 & Master of sciences (Design) & Safety waist, adjustability of the handles, lockability, stability, turnable wheels \\
\hline
\end{tabular}


ANOVA was performed. For not-normally distributed variables, non-parametric Kruskall-Wallis, one-way analyses of variance, was performed. Student's two-tailed t-test (pairwise) was used for comparing the means of the VAS. The differences in the work postures were studied with the $\mathrm{z}$ test for equality of two percentages. A probability level of $\mathrm{p}<0.05$ was accepted as statistically significant.

\section{Results}

During the opening phase of the delivery, the most typical postures of the mothers were standing when using the birthing support and lying on the bed during the traditional delivery (Table 4). During the pushing phase of the delivery, the most typical posture of mother was sitting with the birthing support and half-sitting during the traditional delivery (Table 4).

Table 4. Postures of the Mothers (n=20) During the Opening and Pushing Phases of the Deliveries with the Birthing Support and During the Conventional Deliveries Without the Birthing Support. Several Postures Were Used During One Delivery

\begin{tabular}{|c|c|c|}
\hline $\begin{array}{l}\text { Phase of } \\
\text { Delivery }\end{array}$ & $\begin{array}{l}\text { Delivery with the } \\
\text { Birthing Support }\end{array}$ & $\begin{array}{l}\text { Conventional Delivery } \\
\text { without the Birthing Support }\end{array}$ \\
\hline $\begin{array}{l}\text { Opening } \\
\text { phase }\end{array}$ & $\begin{array}{l}\text { Standing }(\mathrm{n}=5) \\
\text { Side lying }(\mathrm{n}=1) \\
\text { Squatting }(\mathrm{n}=1) \\
\text { Hanging }(\mathrm{n}=1)\end{array}$ & $\begin{array}{l}\text { Lying }(\mathrm{n}=8) \\
\text { Sitting }(\mathrm{n}=4) \\
\text { Standing }(\mathrm{n}=3) \\
\text { Half-sitting }(\mathrm{n}=1) \\
\text { Side lying }(\mathrm{n}=1) \\
\text { Walking }(\mathrm{n}=1)\end{array}$ \\
\hline $\begin{array}{l}\text { Pushing } \\
\text { phase }\end{array}$ & $\begin{array}{l}\text { Sitting }(n=8) \\
\text { Side lying }(n=3)\end{array}$ & $\begin{array}{l}\text { Half-sitting }(n=8) \\
\text { Side lying }(n=5) \\
\text { Sitting on a chair }(n=1) \\
\text { Lying }(n=1)\end{array}$ \\
\hline
\end{tabular}

The midwives worked with a straight back during the pushing phase for $79 \%$ of the studied time when they used the birthing support (Table 5). Without the birthing support, the same proportion was $18 \%$. Standing with both legs straight covered $81 \%$ of the studied time of the midwives during the use of the birthing support and $42 \%$ of the studied time without the support.

The strain perceived in four body parts of the midwives was statistically significantly lower after the deliveries when the birthing support had been used than after the traditional deliveries (Table 6).

In the actual deliveries, the usability of the birthing support according to the mean SUS index was 59 (range 2587.5). The SUS scores of the 10 midwives were the following: 87.5, 77.5, 65, 62.5, 60, 60, 57.5, 32.5 and 25 .

\section{DISCUSSION}

The midwives worked more with a straight back and perceived lower physical strain when the birthing support was used than in the traditional deliveries. In other words, the musculoskeletal exposure was lower during midwives' normal work. The birthing support increased the adjustability of the midwives work environment and made the work level more suitable for the task, as Knezevic et al. [4] has recommended. In addition, the comfort of the midwives was greater because they had a better work posture and were able to see the mother better when the birthing support was used. Good face-to-face contact between the mother and the midwife is important to increase the feeling of presence and decrease the mother's feeling of pain $[7,8,9]$.

The OWAS method was suitable for analysing the work postures of the midwives. The analyses could be done from the video-recordings made by the midwives themselves during the deliveries. The classification of the OWAS method concerning the back, arms, and legs of the midwives was exact enough for this study. The OWAS method has been used in several studies to analyse the musculoskeletal exposure of nurses [19].

In the simulation phase, the best birthing postures, according to the midwives and the mothers, were when the mother sat on the birthing support with the bed crosswise or she laid on her side on the bed with her leg on the birthing support. Both of these postures allowed the midwife to work in an ergonomic posture and see to the object of her work well. The visibility was good also in the traditional posture, when the mother was in a half-sitting position on the bed. However, this posture of the mother demanded that the midwife work with her back bent and twisted. The midwives rated the postures used by the mother while she sat on the traditional, low birthing chair as the poorest. This posture was good for the mother, but the midwife had to squat to work.

The results show that the birthing support enabled the mothers to choose postures that could use gravity to an advantage. They also could relax more easily and could more easily find the correct direction in which to push. Handles of the birthing support were available in different positions that helped the mother activate her abdominal muscles for pushing.

The usability of the birthing support, according to the mean SUS index, was 68 for the simulated situation and 59 for the real deliveries. If these SUS scores are evaluated against emerging benchmarks [16], the usability of the birthing support was good. The SUS index was free, and easy to administer and use. The method is known to be suitable also for products other than software user interfaces [12].

In the user and usability studies, the highest rated features of the birthing support were its adjustability, the design of the back rest, the functioning of the control unit and the design of the whole BS. The VAS proved to be a suitable and easy-to-understand method, and it has been used also in other studies in health care $[11,12]$.

The study was planned in cooperation with researchers, manufacturers, and experienced midwives. In the expert evaluation, 4 experts in ergonomics participated. The expert evaluation was a quick and cheap method for achieving a broad coverage of a whole product. Furthermore, 28 midwives and pregnant women participated in the usability study. The participants were well motivated, and they gave several ideas for product development.

This paper proposes that the birthing support should be considered an ergonomic innovation for use in midwives' 
Table 5. Work Postures (\%) of the Midwives (n=8) During the Pushing Stage of the Real Deliveries According to the OWAS (Ovako Working Posture Analysis System) Variables During 10 Deliveries Using the Birthing Support (1274 Observations) and 10 Conventional Deliveries Without the Birthing Support (1468 Observations)

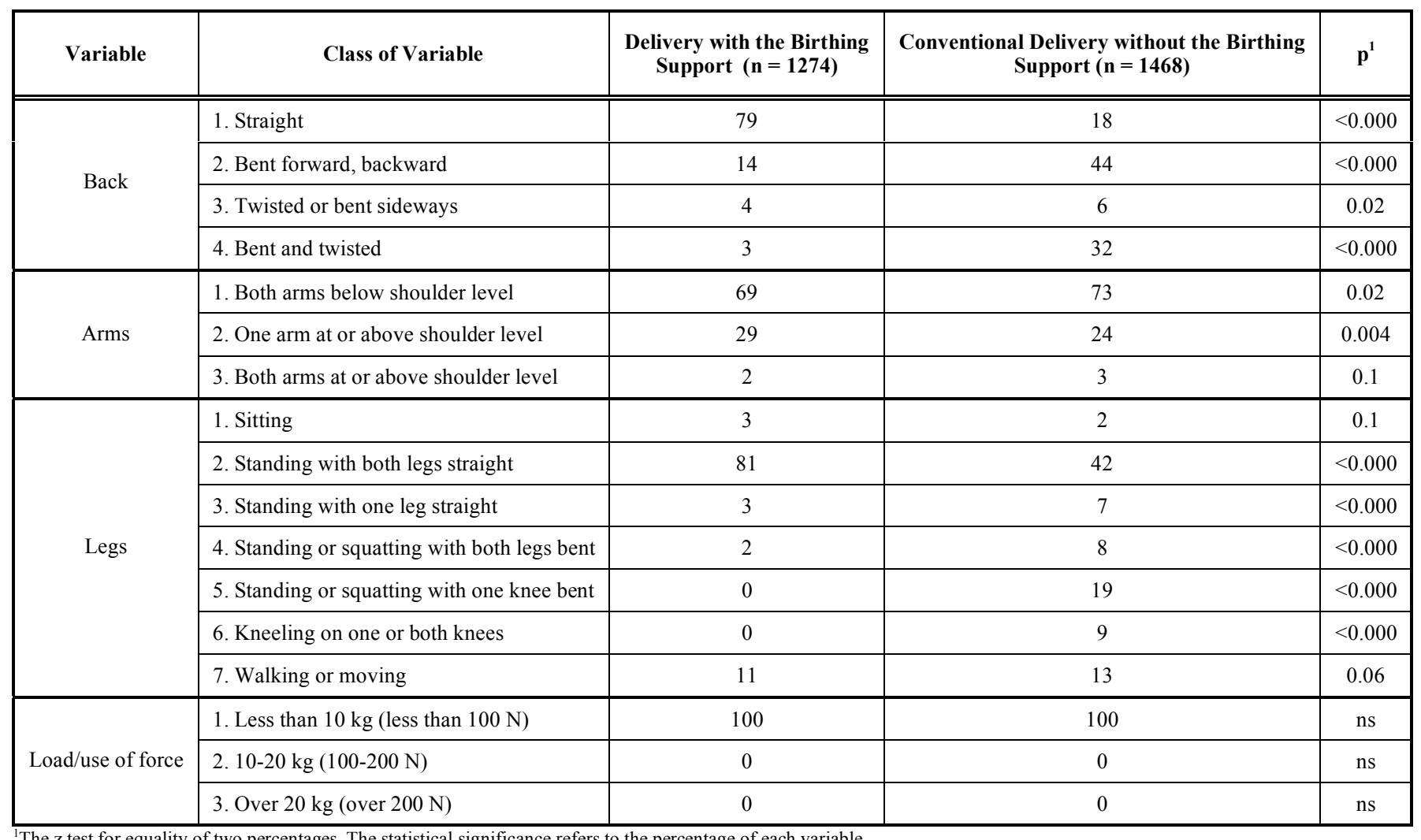

${ }^{1}$ The $\mathrm{z}$ test for equality of two percentages. The statistical significance refers to the percentage of each variable.

work [20]. However, also other ergonomic changes are needed, such as changes in shift schedules [21]. More scientific knowledge is needed about the effectiveness of the use of the birthing support and other ergonomic solutions for midwives' work.

Table 6. Perceived Musculoskeletal Strain (Visual Analogue Scale, VAS, $\mathbf{m m}, 0=$ No Strain, $100=$ Extreme Strain) in Four Body Parts of the Midwives ( $=8$ ) After 10 Real Deliveries Using the Birthing Support and 10 Conventional Deliveries Without the Birthing Support. The Values Given Are Means (SD) and the Statistical Differences (p) Between the Deliveries with the Birthing Support and Conventional Deliveries Without the Birthing Support

\begin{tabular}{|l|c|c|c|c|}
\hline \multirow{2}{*}{\multicolumn{1}{|c|}{ Delivery }} & \multicolumn{4}{|c|}{ Body Part } \\
\cline { 2 - 5 } & $\begin{array}{c}\text { Neck/ } \\
\text { Shoulder }\end{array}$ & Arms & Back & Legs \\
\hline \hline $\begin{array}{l}\text { Delivery with } \\
\text { birthing support }\end{array}$ & $17(11)$ & $28(24)$ & $24(16)$ & $10(9)$ \\
\hline Conventional delivery & $49(20)$ & $66(23)$ & $53(19)$ & $53(22)$ \\
\hline$p^{1}$ & 0.0004 & 0.002 & 0.001 & $<0.0001$ \\
\hline
\end{tabular}

${ }^{1}$ Student t-test between the deliveries.

\section{CONCLUSIONS}

Use of the birthing support increased the adjustability of the midwives work environment and decreased their musculoskeletal exposure at work. The results of this study can be used in developing both ergonomic work for midwives and comfortable birthing postures for mothers. The results can also be used during the practical delivery training of mothers and midwives.

\section{CONFLICT OF INTEREST}

The authors confirm that this article content has no conflict of interest.

\section{ACKNOWLEDGEMENTS}

The authors wish to thank Leena Tamminen-Peter, Special Researcher, and Martti Launis, Senior Expert, for their valuable comments during the expert evaluation, Maria Hirvonen, Special Expert, for her help with the statistical analyses, and Jouko Rytkönen, Graphic Artist, for the drawings. The authors would also like to thank the volunteer midwives, Physicians and mothers who made this project possible. Financial support was provided by the Finnish Work Environment Fund.

\section{REFERENCES}

[1] Nowotny J, Nowotny-Czupryna O, Brzek A, Kowalczyk A, Czupryna K. Body posture and syndromes of back pain. Ortop Traumatol Rehabil 2011; 13(1): 59-71.

[2] Kiyomi K, Masaharu K, Hiroyuki I. Work posture of student midwives using frontal birth assistance techniques and examination of psychological burden - Comparison with experienced midwives. Jpn J Ergon 2006; 42(4): 251-8.

[3] Hignett S. Manual handling risks in midwifery: identification of risk factors. Br J Midwifery 1996; 4: 590-6. 
[4] Knezevic B, Milosevic M, Golubic R, Belosevic L, Russo A, Mustajbegovic J. Work-related stress and work ability among Croatian university hospital midwives. Midwifery 2011; 27: 14653.

[5] Camerino D, Cesana GC, Molteni G, De Vito G, Evaristi C, Latocca R. Job strain and musculoskeletal disorders of Italian nurses. Occup Ergon 2001; 2: 215-23.

[6] Long MH, Johnston V, Bogossian F. Work-related upper quadrant musculoskeletal disorders in midwives, nurses and physicians: a systematic review of risk factors and functional consequences. Appl Ergon 2012; 43(3): 455-67.

[7] Lundgren I, Dahlberg K. Midwives' experience of the encounter with women and their pain during childbirth. Midwifery 2002; 18 : 155-64.

[8] Seibold BA, Miller M, Hall J. Midwives and women in partnership: the ideal and the real. Aust J Adv Nurs 1999; 17: 21-7.

[9] Lundgren I, Dahlberg K. Women's experience of pain during childbirth. Midwifery 1998; 12: 105-10.

[10] Walls C. Do electric patient beds reduce the risk of lower back disorders in nurses? Occup Med 2001; 51: 380-4.

[11] Nevala N, Tamminen-Peter L. Ergonomics and usability of an electrically adjustable shower trolley. Int J Ind Ergon 2004; 34 : 131-8.

[12] Toivonen R, Choi D-S, Nevala N. Ergonomics product development of a mobile workstation for health care. J Usability Stud 2011; 7: 40-50
[13] Sillanpää J, Nyberg M, Laippala P. A new table for work with a microscope, a solution to ergonomic problems. Appl Ergon 2003; 34: 621-8.

[14] Ulrich K, Eppinger S. Product design and development. New York: McGraw-Hill, Inc. 1995.

[15] Price D, McGrath PA, Rafii A, Buckinham B. The validation of visual analogue scale as ratio scale measure for chronic and experimental pain. Pain 1983; 17: 45-56.

[16] Bangor A, Kortum P, Miller J. An empirical evaluation of the system usability scale. Int J Hum-Comput Int 2008; 24: 574-94.

[17] Hignett S. Ergonomic evaluation of electric mobile hoists. Br J Occup Ther 1998; 61: 509-16.

[18] Mattila M, Karwowski W, Vilkki M. Analysis of working postures in hammering tasks on building construction sites using the computerized OWAS method. Appl Ergon 1993; 24: 405-12.

[19] Engels JA, Landeweerd JA, Kant Y. An OWAS-based analysis of nurses' working postures. Ergonomics 1994; 37(5): 909-19.

[20] Martin JL, Norris BJ, Murphy E, Crowe JA. Medical device development: the challenge for ergonomics. Appl Ergon 2008; 39: 271-83.

[21] Kandolin I, Huida O. Individual flexibility: an essential prerequisite in arranging shift schedules for midwives. J Nurs Manage 1996; 4: 213-7.

This is an open access article licensed under the terms of the Creative Commons Attribution Non-Commercial License (http:/creativecommons.org/licenses/by-nc/3.0/) which permits unrestricted, non-commercial use, distribution and reproduction in any medium, provided the work is properly cited. 